\title{
Prevalence of motor impairment in residents of New South Wales, Australia aged 55 years and over: cross-sectional survey of the 45 and Up cohort
}

\author{
R. D. Herbert ${ }^{1,2^{*}}$ D, J. L. Taylor ${ }^{1,3}$, S. R. Lord ${ }^{1,2}$ and S. C. Gandevia ${ }^{1,2}$
}

\begin{abstract}
Background: The population prevalence of many diseases is known. However, little is known of the population prevalence of motor impairments.

Methods: The aim of this study was to determine the point prevalence of specific motor impairments (weakness, fatigue, contracture, impaired balance and impaired coordination) in the population aged 55 years and older resident in New South Wales, Australia in 2018. 55,210 members of the 45 and Up cohort were invited to participate in a follow-up survey that included questions on motor impairment. Responses were received from 20, 141 people (36\%). Calibrated estimates of prevalence of specific motor impairments, and of having at least one motor impairment, were obtained using survey weights based on the known multivariate distributions of age, gender and geographical location (28 regions) in the population.

Results: More than one-third of adults aged over 55 residing in New South Wales have difficulty using their hands, arms or legs. The prevalence of each motor impairment (muscle weakness, fatigue, contracture, impaired balance or impaired coordination) in this population is between 4 and $12 \%$. The prevalence of at least one of these impairments is $21 \%$. The prevalence of at least one impairment in people aged 85 and over is $42 \%$. Women consistently had more difficulty using hands, arms and legs, and more motor impairment, than men. Difficulty using hands, arms and legs and the prevalence of all motor impairments, especially poor balance, greatly increased with age.

Conclusion: The prevalence of specific motor impairments in older Australian adults is high - comparable to that of the most prevalent diseases. There may be merit in considering motor impairment as a significant public health problem in its own right.
\end{abstract}

Keywords: Motor impairment, Weakness, Fatigue, Contracture, Balance, Coordination

\footnotetext{
* Correspondence: r.herbert@neura.edu.au

${ }^{1}$ Neuroscience Research Australia (NeuRA), Barker St, Randwick, NSW 2031,

Australia

¿University of New South Wales, Sydney, Australia

Full list of author information is available at the end of the article
}

(c) The Author(s). 2020 Open Access This article is licensed under a Creative Commons Attribution 4.0 International License, which permits use, sharing, adaptation, distribution and reproduction in any medium or format, as long as you give appropriate credit to the original author(s) and the source, provide a link to the Creative Commons licence, and indicate if changes were made. The images or other third party material in this article are included in the article's Creative Commons licence, unless indicated otherwise in a credit line to the material. If material is not included in the article's Creative Commons licence and your intended use is not permitted by statutory regulation or exceeds the permitted use, you will need to obtain permission directly from the copyright holder. To view a copy of this licence, visit http://creativecommons.org/licenses/by/4.0/ The Creative Commons Public Domain Dedication waiver (http://creativecommons.org/publicdomain/zero/1.0/) applies to the data made available in this article, unless otherwise stated in a credit line to the data. 


\section{Background}

Studies of disease prevalence contribute to quantification of disease burden [1]. The current study is concerned with the prevalence of motor impairments instead of the prevalence of disease.

Motor impairments interfere with motor ability. This study focuses on five motor impairments: muscle weakness, fatigue, contracture, impaired balance and impaired coordination. Fatigue is a complex motor impairment because it includes both a reduction in the capacity of a muscle to produce force during sustained motor tasks and an increased sense of effort, exhaustion or weariness [2]. Impaired balance is also complex because it can reflect peripheral failure or failure of multisensory integration and high level executive functions [3].

Motor impairments can have many causes. For example muscle weakness may be caused by stroke, neuromuscular disease or prolonged bed rest. Nonetheless, motor impairments with diverse causes can share common mechanisms, have the same consequences, contribute to the same clinical syndromes and respond to the same interventions. So, to use the same example, muscle weakness may be mediated by muscle atrophy, impair ambulation, increase risk of falling and respond to exercise therapy, regardless of whether the weakness is caused by stroke, neuromuscular disease or bed rest. To the extent that motor impairments share common mechanisms, have the same consequences and respond to the same interventions it may be useful to study motor impairments, not just the diseases or injuries that cause motor impairments.

While there have been many disease-specific studies of the prevalence of motor impairment (e.g. prevalence of fatigue in multiple sclerosis [4]), there have been relatively few population-based studies. Notable exceptions include studies of population prevalence of weakness in Brasil [5], USA [6-8] and Ecuador [9]; fatigue in Norway [10], England [11] and USA [12]; and impaired balance and coordination in Brasil [13], Norway [14], Colombia [15] and the USA [16]. Nonetheless, with the possible exception of estimates of the prevalence of weakness, estimates of the prevalence of specific motor impairments are sparse. There do not appear to be any data on the population prevalence of contracture [17].

As there have been relatively few population-based studies of the prevalence of motor impairment and, to our knowledge, no population-based studies of the prevalence of specific motor impairments in the Australian population, we sought to determine the prevalence of weakness, fatigue, contracture, impaired balance and impaired coordination in residents of the state of New South Wales aged 55 years and older in 2018.

\section{Methods}

The 45 and Up cohort was assembled between 2006 and 2009 by sending invitations to New South Wales residents aged 45 and over who were randomly sampled from the Department of Human Services (Medicare Australia) enrolment database [18]. The database includes people in aged-care facilities. Medicare is the system that provides free or subsidised health services to all Australian citizens and residents, as well as some non-residents. Invitations were sent by mail. By design, there was oversampling of residents in rural areas and people aged over 80 . All people living in remote areas were invited to participate. The response rate was approximately $18 \%$. People who had not been invited to participate could request to participate in the study but only $0.1 \%$ of the cohort was recruited in this way. Recruitment continued until December 2009 when there were 267,153 participants in the cohort. At the time of entry into the study, participants provided extensive demographic and health data. Data were self-reported or provided by a proxy (e.g., family member or carer).

There have been two further waves of date collection from this cohort. The second of these is currently underway: in each of the years 2018-2021, invitations to provide follow-up data have been or will be sent to approximately one-quarter of those who are alive and contactable and who have not asked to withdraw from the study. At 1 January 2018, 89\% of the cohort was alive. In 2018, invitations were sent to 55,210 participants. This paper summarises the data that 20,141 participants ( $36 \%$ of those invited) provided in 2018 by mail or email in response to those invitations.

In the 2018 follow-up, participants were asked to respond to questions about motor impairment. Specifically, they were asked:

"In general, how would you rate your balance?" Response options were "poor", "fair", "good", "very good" and "excellent". (In the subsequent analyses, participants were assumed to have impaired balance if they rated their balance as poor.)

"Do you have any difficulty using your hands, arms or legs to carry out everyday activities?" If the response was "yes", additional response options for each of "hands", "arms" and "legs" were "neither", "one" and "both".

"If you have difficulty, is the difficulty due to any of the following?" Response options, for each of "weakness", "muscles tire easily - fatigue", "limited joint movement from contracture" and "poor coordination clumsiness" were "hand/s", "arm/s" and leg/s". 
The target population for this study was the 2,215,637 people residing in New South Wales aged 55 years and over in 2018. To estimate prevalence in the target population as accurately as possible, study participants were assigned sampling weights based on three control variables: age, sex and geographical location. Geographical location was categorised using the 28-level 2011 Statistical area level 4 (SA4) code [19]. Sampling weights were calculated using the multivariate distributions of the control variables in the population from the 2015 Australian Statistical Geography Standard (ASGS) survey conducted by the Australian Bureau of Statistics. (2015 was the last year in which the Bureau used 2011 SA4 codes.) Sampling weights for each of 224 cells (4 age categories $\times 2$ sexes $\times 28$ geographical areas) were obtained by dividing the count in the population by the count in the sample. The weights were scaled up by a factor of 1.063 to account for the population growth in New South Wales from 2015 to 2018 [20]. Crude estimates of prevalence were adjusted by the sampling weights using 'pweight's in Stata 15.1.

\section{Results}

The mean sampling weight for the 20,141 participants who provided follow-up data was 115 , indicating that on average, each survey participant represented 115 people in the target population. After truncating survey weights at a maximum of 500 (necessary for just $0.2 \%$ of the cohort) the coefficient of variation of the survey weights was 0.61 , indicating that the distribution of age, sex and geographical location in the sample was moderately representative of the age, sex and geographical location of the population. Most of the 20,141 participants provided complete responses. As a typical example, 19,277 participants (96\%) provided data on ability to use hands, arms or legs.

A large proportion of the target population $(37.1 \%$, 95\% CI 36.3 to $37.9 \%)$ reported difficulty using hands, arms or legs. Table 1 shows the distribution of difficulty using hands, arms and legs by age and sex.

There were moderate associations between prevalence of difficulty using hands, arms or legs and each of the control variables used to obtain sampling weights: the

Table 1 Estimated prevalence (\%) of difficulty using hands, arms or legs, by age and sex

\begin{tabular}{|c|c|c|c|}
\hline Age & Men $(\boldsymbol{N}=1,055,316)$ & Women $(N=1,160,321)$ & All $(\boldsymbol{N}=2,215,637)$ \\
\hline \multicolumn{4}{|c|}{ Difficulty using hands, arms or legs } \\
\hline $55-64(N=930,520)$ & 30.9 (28.9 to 33$)$ & 35.8 (34.1 to 37.5$)$ & 33.4 (32.1 to 34.7$)$ \\
\hline $65-74(N=719,450)$ & 32.7 (31 to 34.4 ) & 37.1 (35.6 to 38.6$)$ & 34.9 (33.8 to 36.1$)$ \\
\hline $75-84(N=393,247)$ & 36.5 (33.8 to 39.2) & 45.1 (42.6 to 47.6$)$ & 41.1 (39.3 to 43) \\
\hline $85+(N=172,420)$ & 52.1 (47.6 to 56.7$)$ & 59.6 (55.1 to 63.9) & 56.8 (53.6 to 60 ) \\
\hline Total $(55+)(N=2,215,637)$ & 33.7 (32.5 to 34.9 ) & 40.1 (39.1 to 41.2) & 37.1 (36.3 to 37.9 ) \\
\hline \multicolumn{4}{|l|}{ Difficulty using hands } \\
\hline $55-64(N=930,520)$ & 9.5 (8.3 to 10.9$)$ & $14.2(13$ to 15.5$)$ & 11.8 (11 to 12.7$)$ \\
\hline $65-74(N=719,450)$ & $10(8.9$ to 11.1$)$ & 14.4 (13.3 to 15.5$)$ & $12.1(11.4$ to 12.9$)$ \\
\hline $75-84(N=393,247)$ & 10.3 (8.7 to 12.2 ) & $16.8(15$ to 18.7$)$ & $13.3(12.1$ to 14.6$)$ \\
\hline $85+(N=172,420)$ & 17.5 (14.3 to 21.2$)$ & $25.2(21.5$ to 29.4$)$ & $20.3(17.8$ to 23.1$)$ \\
\hline Total $(55+)(N=2,215,637)$ & 10.6 (9.8 to 11.4$)$ & $15.3(14.6$ to 16.1$)$ & $12.8(12.3$ to 13.4$)$ \\
\hline \multicolumn{4}{|l|}{ Difficulty using arms } \\
\hline $55-64(N=930,520)$ & 8.2 (7.1 to 9.4$)$ & $9.2(8.2$ to 10.2$)$ & 8.7 (7.9 to 9.5) \\
\hline $65-74(N=719,450)$ & 7.8 (6.9 to 8.8$)$ & 9.3 (8.4 to 10.3 ) & 8.6 (7.9 to 9.3$)$ \\
\hline $75-84(N=393,247)$ & 9 (7.4 to 10.8$)$ & 11.9 (10.3 to 13.6$)$ & 10.3 (9.2 to 11.6$)$ \\
\hline $85+(N=172,420)$ & $13.2(10.4$ to 16.7$)$ & 19.1 (15.7 to 23$)$ & 15.3 (13.1 to 17.9$)$ \\
\hline Total $(55+)(N=2,215,637)$ & 8.7 (8 to 9.4$)$ & 10.3 (9.6 to 10.9 ) & 9.4 (9 to 9.9 ) \\
\hline \multicolumn{4}{|l|}{ Difficulty using legs } \\
\hline $55-64(N=930,520)$ & 14.5 (13 to 16.1$)$ & 15.5 (14.2 to 16.8$)$ & 15 (14 to 16$)$ \\
\hline $65-74(N=719,450)$ & 16.1 (14.8 to 17.5$)$ & 17.7 (16.5 to 18.9$)$ & 16.9 (16 to 17.8$)$ \\
\hline $75-84(N=393,247)$ & 19.8 (17.6 to 22.2) & 26.4 (24.2 to 28.7$)$ & 22.8 (21.2 to 24.5$)$ \\
\hline $85+(N=172,420)$ & 32.3 (28.2 to 36.6$)$ & 34.8 (30.6 to 39.2) & 33.2 (30.2 to 36.4 ) \\
\hline Total $(55+)(N=2,215,637)$ & 17.7 (16.7 to 18.7$)$ & 19.2 (18.4 to 20.1$)$ & $18.4(17.8$ to 19.1$)$ \\
\hline
\end{tabular}

Prevalence is given as a percentage of people in that cell. Marginal totals (Ns) are for the population (not the sample) based on Australian Bureau of Statistics data for 2018 [20]. The mean age of men and women within each age category differed by less than 0.2 years 
odds ratio (OR) for age 85+ compared to age 55-64 was 2.6 (95\% CI 2.2 to 2.9 ), the OR for women compared to men was 1.23 (95\% CI 1.16 to 1.31), and the OR for the geographical area with highest compared to lowest prevalence was 1.9 (95\% CI 1.4 to 2.6). Nonetheless, the crude estimates and adjusted estimates of population prevalences of motor impairment were very similar. Adjusted estimates are reported here. The estimated prevalences of muscle weakness, fatigue, contracture, impaired balance and impaired coordination are shown in Table 2.

\section{Discussion}

To our knowledge these are the first population-based estimates of the prevalence of specific motor impairments in the Australian population. Unlike most previous

Table 2 Estimated prevalence (\%) of motor impairments by age and sex

\begin{tabular}{|c|c|c|c|}
\hline Age & Men & Women & All \\
\hline \multicolumn{4}{|l|}{ Weakness } \\
\hline $55-64$ & 7.1 (6 to 8.3$)$ & 11.4 (10.4 to 12.6$)$ & $9.3(8.6$ to 10.1$)$ \\
\hline $65-74$ & 8.8 (7.8 to 9.9) & $12.3(11.3$ to 13.4$)$ & 10.6 (9.9 to 11.3$)$ \\
\hline $75-84$ & 11.7 (9.9 to 13.8$)$ & 16.1 (14.3 to 18.1$)$ & 14.1 (12.8 to 15.5$)$ \\
\hline $85+$ & $21.2(17.7$ to 25.1$)$ & 22.5 (19 to 26.4 ) & 22 (19.4 to 24.8) \\
\hline Total (55+) & 9.3 (8.6 to 10.1$)$ & 13.6 (12.9 to 14.4$)$ & $11.6(11$ to 12.1$)$ \\
\hline \multicolumn{4}{|l|}{ Fatigue } \\
\hline $55-64$ & 5.5 (4.5 to 6.6$)$ & $6.2(5.4$ to 7$)$ & 5.8 (5.2 to 6.5$)$ \\
\hline $65-74$ & 6.5 (5.7 to 7.5$)$ & 8.3 (7.5 to 9.2 ) & 7.4 (6.9 to 8.1$)$ \\
\hline $75-84$ & 10.8 (9.1 to 12.7$)$ & 11.6 (10.1 to 13.3$)$ & $11.2(10.1$ to 12.4$)$ \\
\hline $85+$ & 18.9 (15.6 to 22.8$)$ & 21.6 (18.1 to 25.5$)$ & 20.6 (18 to 23.4) \\
\hline Total (55+) & 7.5 (6.9 to 8.2$)$ & 9.3 (8.7 to 9.9) & 8.5 (8 to 8.9 ) \\
\hline \multicolumn{4}{|l|}{ Contracture } \\
\hline $55-64$ & 7.1 (6.1 to 8.3 ) & 6.3 (5.5 to 7.3 ) & 6.7 (6 to 7.4$)$ \\
\hline $65-74$ & 8 (7 to 9.1$)$ & 7.9 (7.1 to 8.8$)$ & 8 (7.3 to 8.6$)$ \\
\hline $75-84$ & 9.8 (8.2 to 11.7$)$ & $10.2(8.7$ to 11.8$)$ & 10 (8.9 to 11.3$)$ \\
\hline $85+$ & $15.2(12.1$ to 18.9$)$ & $12.3(9.7$ to 15.4$)$ & 13.4 (11.3 to 15.7$)$ \\
\hline Total $(55+)$ & 8.4 (7.7 to 9.1$)$ & 8.1 (7.5 to 8.7 ) & 8.2 (7.8 to 8.7$)$ \\
\hline \multicolumn{4}{|c|}{ Impaired balance } \\
\hline $55-64$ & 1.7 (1.2 to 2.4$)$ & 2.4 (1.9 to 2.9$)$ & 2.1 (1.7 to 2.5$)$ \\
\hline $65-74$ & 2.3 (1.8 to 2.8 ) & 3.8 (3.2 to 4.5$)$ & $3(2.7$ to 3.5$)$ \\
\hline $75-84$ & 5.4 (4.3 to 6.8$)$ & 7.5 (6.3 to 8.9$)$ & 6.5 (5.7 to 7.5$)$ \\
\hline $85+$ & $13.7(10.9$ to 17.1$)$ & 16.7 (13.6 to 20.3) & 15.6 (13.3 to 18.1$)$ \\
\hline Total (55+) & 3.2 (2.8 to 3.7$)$ & 5.1 (4.6 to 5.6$)$ & 4.2 (3.9 to 4.6$)$ \\
\hline \multicolumn{4}{|c|}{ Impaired coordination } \\
\hline $55-64$ & 2.5 (1.9 to 3.3$)$ & 2.3 (1.8 to 2.8$)$ & 2.4 (2 to 2.8$)$ \\
\hline $65-74$ & 2.8 (2.3 to 3.5$)$ & 3.4 (2.8 to 4$)$ & 3.1 (2.7 to 3.6$)$ \\
\hline $75-84$ & 3.9 (3 to 5$)$ & 5.6 (4.5 to 6.9$)$ & 4.8 (4.1 to 5.7$)$ \\
\hline $85+$ & 9.8 (7.5 to 12.7$)$ & $7.9(5.8$ to 10.6$)$ & 8.6 (7 to 10.5$)$ \\
\hline Total $(55+)$ & 3.3 (2.9 to 3.7$)$ & 3.7 (3.3 to 4.2$)$ & 3.5 (3.2 to 3.8$)$ \\
\hline \multicolumn{4}{|c|}{ Any (at least one) of these impairments } \\
\hline $55-64$ & $13.7(12.3$ to 15.3$)$ & $17.6(16.3$ to 19$)$ & $15.7(14.7$ to 16.7$)$ \\
\hline $65-74$ & $16.5(15.2$ to 17.9$)$ & 21.1 (19.9 to 22.5$)$ & $18.8(17.9$ to 19.8$)$ \\
\hline $75-84$ & 23.4 (21.1 to 25.8$)$ & 28.5 (26.3 to 30.8) & 26.1 (24.5 to 27.8$)$ \\
\hline $85+$ & $37.9(33.6$ to 42.4$)$ & 44 (39.7 to 48.5$)$ & 41.8 (38.6 to 45$)$ \\
\hline Total $(55+)$ & $17.7(16.8$ to 18.7$)$ & $23.2(22.3$ to 24.1$)$ & 20.6 (19.9 to 21.3$)$ \\
\hline
\end{tabular}

Prevalence is given as a percentage of people in that cell 
population-based studies of motor impairment this study estimates the prevalence of multiple motor impairments. We estimate that, in residents of New South Wales aged 55 and over, the prevalence of specific impairments is as follows: weakness $12 \%$, fatigue $9 \%$, contracture $8 \%$, impaired balance $4 \%$ and impaired coordination $4 \%$. The prevalence of having at least one of these impairments is $21 \%$. In the population aged 85 and over, the prevalence of at least one of these impairments is $42 \%$. In comparison, the three most prevalent global diseases (Level 3 Global Burden of Diseases, Injuries, and Risk Factors Study causes) are oral disorders, headache disorders and latent tuberculosis infection, with estimated global prevalences (across all ages and all countries) in 2017 of 46, 40 and $26 \%$ respectively (calculated from reference [1] assuming a global population of 7.511 billion in 2017 [21]).

Two clear patterns emerge from the data. First, women consistently experience more difficulty using their hands, arms or legs and have more motor impairments than men. This was particularly evident for difficulty using hands, and for weakness and fatigue. Second, there was a large increase with age in difficulty using hands, arms or legs and in the prevalence of all motor impairments. There was at least twice the prevalence of all motor impairments in the group aged $85+$ compared to the group aged 55-64. The prevalence of poor balance in the group aged $85+$ was more than seven times that in the group aged 55-64.

Our estimates of the population prevalence of specific motor impairments are generally comparable to or lower than previous estimates. For example, it has been estimated that the population prevalence of weakness is $4-18 \%$ at $60-69$ years, $9-34 \%$ at $70-79$ years, and $26-$ $68 \%$ at $80+$ years $[7,9]$, and $5-31 \%$ at $60+$ years $[5,8]$. Estimates for fatigue are $38 \%$ at $18-45$ years [11], $12 \%$ at $18+$ years [12] and $22 \%$ at $19-80$ years [10]. Estimates for impaired balance or coordination are 8-14\% at $60-69$ years, $16-17 \%$ at $70-79$ years, and $39-46 \%$ at $80+$ years [14, 15], $16 \%$ at $60+$ years [13] and $28 \%$ at $65+$ years [16]. Other studies have also report that women have higher prevalences of impairment [22] and that prevalence of weakness and impaired balance increase markedly with age $[7,9,14,15]$.

One explanation for the moderate variation in reported prevalences is that there were differences in case definitions across studies. Most previous studies of the population prevalence of weakness have defined cases as people with grip strength less than a specific threshold. In those studies grip strength was measured objectively. In the present study, cases or their surrogates self-reported that they had difficulty using their hands, arms or legs to carry out everyday activities because of weakness. While this approach relies on subjective selfreports, it explicitly assesses the weakness of all appendicular muscles (though it does not assess weakness of axial muscles). Previous studies of the population prevalence of specific motor impairments have not explicitly required that the motor impairment limits motor ability, although many studies have demonstrated associations between fatigue and motor ability (e.g., [23]). Studies of the prevalence of fatigue have used definitions of fatigue that reflect both the physical and the emotional or perceptual dimensions of fatigue. Interestingly, a population-based study that explicitly measured different dimensions of fatigue found similar distributions of physical and mental fatigue [22]. The present study asked participants if their "muscles tire easily" causing "difficulty using your hands, arms or legs to carry out everyday activities". This wording emphasises the physical dimension of fatigue. Several population-based studies have quantified balance impairment using the Short Physical Performance Battery. One study conducted in the USA that used case definitions similar to those used here found that $28 \%$ of participants aged $65+$ reported "problems with balance or coordination" whereas $4 \%$ of our population aged 55+ reported difficulty using hands, arms or legs to carry out everyday activities because of poor coordination and $4 \%$ reported poor balance.

The current study has several limitations. First, motor impairments were self-reported or reported by a surrogate. Self- or surrogate-reported presence or absence of a motor impairment may not always correspond with the judgement of a trained observer. This is likely to be particularly problematic for the estimates of contracture because it is likely many respondents including some who had contractures did not clearly understand what was meant by this term. Second, the survey provided data on the prevalence of motor impairments that respondents perceived "caused difficulty using the limbs". It is likely that the level of "difficulty" experienced by respondents varied from mild to severe. A third limitation is that the response rate was low. Responses were obtained from $36 \%$ of the cohort who were invited to provide follow-up data in 2018, and the cohort consisted of the $18 \%$ who responded to the initial survey between 2006 and 2009. Thus the data provide potentially biased estimates of prevalence. It was possible to significantly reduce the potential for bias because the sample was obtained from a well-defined and well-characterised population, enabling tight calibration using the known three-way distribution of age, sex and geographical area (224 cells). Nonetheless, there may still be substantial bias if factors other than age, sex and geographical location were strongly associated with both response frequency and the prevalence of motor impairment but not with age, sex or geographical area [24].

This study shows that the prevalence of five specific motor impairments is high in New South Wales residents aged 55 and over. These impairments probably 
mediate geriatric syndromes [25] that are major causes of morbidity in older populations. Historically, epidemiologists have focused on quantifying the prevalence of diseases and, to a lesser extent, on the prevalence of injuries, risk factors for disease (such as high blood pressure) and non-motor impairments (such as blindness). To the extent that highly prevalent motor impairments share common mechanisms, have similar consequences and respond to the same interventions there may be merit in considering motor impairment as a significant public health problem in its own right.

\section{Conclusion}

The prevalence of specific motor impairments in older Australian adults is high - comparable to that of the most prevalent diseases. In this population, motor impairment is more prevalent in women than men, and increases greatly with age. There may be merit in considering motor impairment as a significant public health problem in its own right.

\section{Abbreviations}

ASGS: Australian Statistical Geography Standard; SA4: Statistical area level 4; OR: Odds ratio

\section{Acknowledgements}

None.

\section{Authors' contributions}

SG, SL, JT and RH conceived the study, obtained grant funding, planned the study and contributed to framing of the questions. $\mathrm{RH}$ analysed the data. SG $\mathrm{SL}$, JT and $\mathrm{RH}$ contributed to the interpretation of the data. $\mathrm{RH}$ drafted the manuscript. All authors reviewed the manuscript and read and approved the final manuscript.

\section{Funding}

The study was funded with a program grant from the Australian NHMRC. The funder had no role in the study.

\section{Availability of data and materials}

The data that support the findings of this study are available from The Sax Institute but restrictions apply to the availability of these data, which were used under license for the current study, and so are not publicly available. Data may be made available upon request to The Sax Institute.

\section{Ethics approval and consent to participate}

The study was conducted as part of the Sax Institute's 45 and Up study [3]. The 45 and Up study was approved by the University of New South Wales Human Research Ethics Committee (HC15408). Participants provided informed written consent when recruited at baseline to participate in the 45 and Up Study baseline and for subsequent follow-up surveys.

\section{Consent for publication}

Not applicable.

\section{Competing interests}

None.

\section{Author details}

'Neuroscience Research Australia (NeuRA), Barker St, Randwick, NSW 2031, Australia. ${ }^{2}$ University of New South Wales, Sydney, Australia. ${ }^{3}$ Edith Cowan University, Perth, Australia.
Received: 22 April 2020 Accepted: 25 August 2020

Published online: 04 September 2020

\section{References}

1. GBD 2017 Disease and Injury Incidence and Prevalence Collaborators. Global, regional, and national incidence, prevalence, and years lived with disability for 354 diseases and injuries for 195 countries and territories, 1990-2017: a systematic analysis for the global burden of disease study 2017. Lancet. 2018:392(10159):1789-858.

2. Kluger BM, Krupp LB, Enoka RM. Fatigue and fatigability in neurologic illness. Proposal for a unified taxonomy. Neurology. 2013:80:409-16.

3. Forbes PA, Chen A, Blouin J-S: Sensorimotor control of standing balance. In: Handbook of Clinical Neurology Volume 159: Balance, Gait and Falls. Day BL, Lord SR. Amsterdam: Elsevier; 2019.

4. Wood B, van der Mei IA, Ponsonby AL, Pittas F, Quinn S, Dwyer T, Lucas RM, Taylor BV. Prevalence and concurrence of anxiety, depression and fatigue over time in multiple sclerosis. Mult Scler J. 2013;19(2):217-24.

5. Alexandre TDS, Duarte YAO, Santos JLF, Lebrao ML. Prevalence and associated factors of sarcopenia, dynapenia, and sarcodynapenia in community-dwelling elderly in Sao Paulo - SABE Study. Revista Brasileira de Epidemiologia. 2019;21(Suppl 02):e180009.

6. Armour BS, Courtney-Long EA, Fox MH, Fredine H, Cahill A. Prevalence and causes of paralysis-United States, 2013. Am J Public Health. 2016;106(10): 1855-7.

7. Batsis JA, Germain CM, Vasquez E, Bartels SJ. Prevalence of weakness and its relationship with limitations based on the foundations for the National Institutes for Health project: data from the Health and Retirement Study. Eur J Clin Nutr. 2016;70(10):1168-73.

8. Looker AC, Wang C-Y. Prevalence of reduced muscle strength in older US adults: United States, 2011-2012. NCHS Data Brief; 2015. p. 179.

9. Orces $\mathrm{CH}$. Prevalence of clinically relevant muscle weakness and its association with vitamin D status among older adults in Ecuador. Aging Clin Exp Res. 2017:29(5):943-9.

10. Loge $\mathrm{JH}$, Ekeberg $\mathrm{O}$, Kaasa S. Fatigue in the general Norwegian population: normative data and associations. J Psychosom Res. 1998:45:53-65.

11. Pawlikowska T, Chalder T, Hirsch SR, Wallace P, Wright DJM, S.C. W: population based study of fatigue and psychological distress. BMJ. 1994;308: 763-6.

12. Jason LA, Jordan KM, Richman JA, Rademaker AW, Huang C-F, McCready W, Shlaes J, King CP, Landis D, Torres S, et al. A community-based study of prolonged fatique and chronic fatigue. J Health Psychol. 1999:4:9-26.

13. Bushatsky A, Alves LC, Duarte YAO, Lebrao ML. Factors associated with balance disorders of elderly living in the city of Sao Paulo in 2006: evidence of the Health, Well-being and Aging (SABE) Study. Revista Brasieira de Epidemiologia. 2019;21Suppl 02(Suppl 02):e180016.

14. Bergland A, Strand BH. Norwegian reference values for the short physical performance battery (SPPB): the Tromso study. BMC Geriatr. 2019;19(1):216.

15. Ramírez-Vélez R, Pérez-Sousa MA, Venegas-Sanabria LC, Cano-Gutierrez CA Hernández-Quiñonez PA, Rincón-Pabón D, García-Hermoso A, ZambomFerraresi F, Sáez de Asteasu ML, Izquierdo M. Normative values for the Short Physical Performance Battery (SPPB) and their association with anthropometric variables in older Colombian adults. The SABE Study, 2015. Front Med. 2020:7.52

16. Patel KV, Phelan EA, Leveille SG, Lamb SE, Missikpode C, Wallace RB, Guralnik JM, Turk DC. High prevalence of falls, fear of falling, and impaired balance in older adults with pain in the United States: findings from the 2011 National Health and Aging Trends Study. J Am Geriatr Soc. 2014; 62(10):1844-52

17. Fergusson D, Hutton B, Drodge A. The epidemiology of major joint contractures: a systematic review of the literature. Clin Orthop. 2006; 456:22-9.

18. 45 and Up Study Collaborators, Banks E, Redman S, Jorm L, Armstrong B, Bauman A, Beard J, Beral V, Byles J, Corbett S, et al. Cohort profile: the 45 and up study. Int J Epidemiol. 2008:37(5):941-7.

19. Australian Statistical Geography Standard (ASGS): Volume 1 - Main Structure and Greater Capital City Statistical Areas, 2011 (1270.0.55.001).

20. Australian Bureau of Statistics: Regional population by age and sex, Australia, 2018. 2019 https://wwwabsgovau/ausstats/abs@nsf/mf/32350/. accessed 4 November 2019.

21. World Bank: Population, total. 2019 https://dataworldbankorg/indicator/ SPPOPTOTL accessed 29 August 2019. 
22. Engberg I, Segerstedt J, Waller $G$, Wennberg P, Eliasson M. Fatigue in the general population- associations to age, sex, socioeconomic status, physical activity, sitting time and self-rated health: the northern Sweden MONICA study 2014. BMC Public Health. 2017;17(1):654.

23. Soares WJ, Lima CA, Bilton TL, Ferrioli E, Dias RC, Perracini MR. Association among measures of mobility-related disability and self-perceived fatigue among older people: a population-based study. Brazilian J Phys Ther. 2015; 19(3):194-200.

24. Mercer AW, Kreuter F, Keeter S, Stuart EA. Theory and practice in nonprobability surveys. Public Opin Q. 2017;81(S1):250-71.

25. Inouye SK, Studenski SA, Tinetti ME, Kuchel GA. Geriatric syndromes: clinical, research and policy implications of a core geriatric concept. J Am Geriatr Soc. 2007;55:780-91.

\section{Publisher's Note}

Springer Nature remains neutral with regard to jurisdictional claims in published maps and institutional affiliations.

Ready to submit your research? Choose BMC and benefit from:

- fast, convenient online submission

- thorough peer review by experienced researchers in your field

- rapid publication on acceptance

- support for research data, including large and complex data types

- gold Open Access which fosters wider collaboration and increased citations

- maximum visibility for your research: over $100 \mathrm{M}$ website views per year

At BMC, research is always in progress.

Learn more biomedcentral.com/submissions 